\title{
CARTOgRAFias da PESQUiSA-AÇÃo: EM BUSCA dE DESLOCAMENTOS DA EPISTEMOLOGIA DO SUL ${ }^{1}$
}

\author{
Lumárya Souza de Sousa \& Thaiane Oliveira
}

\begin{abstract}
Resumo
A proposta deste trabalho é discutir sobre a pesquisa-ação como uma das possibilidades de desenvolvimento de uma epistemologia do Sul, na qual possa se atrelar o conhecimento científico e outras ecologias de saberes. Propomos, neste trabalho, realizar uma cartografia sobre o que vem sendo desenvolvido sobre pesquisa-ação no Brasil, buscando discutir esta dimensão de produção de conhecimento a partir de perspectivas que busquem romper o abismo entre ciência colonizadora e a ciência invisibilizada na geopolítica do conhecimento científico. Assim, nossa proposta busca compreender o que vem sido produzido sobre pesquisa-ação no Brasil, quem são os atores que estão desenvolvendo este tipo de pesquisa e como esta pode ser entendida como própria de uma epistemologia do Sul.
\end{abstract}

Palavras-chave

Ciência invisível; epistemologia do Sul; pesquisa-ação; Sul Global

\begin{abstract}
The purpose of this paper is to discuss action research as one of the possibilities for the development of an epistemology of the South, in which scientific knowledge and other ecologies of knowledge can be linked. In this work, we propose a mapping of what has been developed on action research in Brazil, seeking to discuss this dimension of knowledge production from perspectives which seek to break the gap between colonizing and invisibilized science in the geopolitics of scientific knowledge. Thus, our proposal seeks to answer what has been produced on action research in Brazil, who are the actors that are developing this type of research and how it can be understood as belonging to an epistemology of the South.
\end{abstract}

KeYwORDS

Action research; epistemology of the South; invisible science; Global South

\section{INTRODUÇÃo}

A produção científica é calcada não apenas em normas imperativas institucionais, tal como já apontado na década de 1940 por Robert Merton (1972), sobre as premissas da ciência moderna, na qual os resultados das investigações científicas são pertencentes a toda a sociedade, mas também envolve uma série de disputas de capital e poder para

\footnotetext{
' Parte desta pesquisa foi apoiada pela agência DAAD (Alemanha), referente ao projeto Literacias do Global South, realizada após visita de cooperação internacional com a Universidade de Tubingen em janeiro de 2018, com fundos do Ministério Federal Alemão de Educação e Investigação.
} 
domínio dos espaços de circulação científica global². O próprio sociólogo da ciência já reconhecia, ainda na primeira metade do século $X X$, que tais normas não eram imperativas e que uma série de outras vaidades e capitais simbólicos afetam diretamente 0 ethos científico (Merton, 1968). Contudo, mais do que dinâmicas internas próprias de micro-organizações sociais e disputas de capitais simbólicos, o ecossistema científico também está consolidado a partir de disputas de capitais econômicos em uma geopolítica do conhecimento baseada na privatização do saber. Neste ecossistema científico, vemos a predominância de um conjunto de empresas editoriais que ditam as normas de qualidade do conhecimento científico, formando um oligopólio no qual seu lucro é baseado na comercialização do conhecimento (Larivière, Haustein \& Mongeon, 2015) e elevam ao status de hegemonia um conjunto de países que vêm dominando o mercado científico há mais de 350 anos.

Neste ecossistema científico há uma separação abissal (Santos, 2007) entre o que é hegemônico e o que é periférico, entre o que é visível e o que está sendo invisibilizado, reforçando a ideia da existência de diferentes circuitos de produção científica. Mais ainda, outras dicotomias são traçadas em torno da ciência moderna, que se pauta na legitimação da produção de conhecimentos assentes no racionalismo e distinguindo o conhecimento científico e o popular, elevando barreiras que separam o que é validado pela ciência e o que não é reconhecido pela mesma. Portanto, torna-se necessário desenvolver formas de pensamento que busquem superar essas dicotomias da circulação científica, permitindo a superação destas distinções da produção de diferentes conhecimentos, próprias de um pensamento pós-abissal (Santos, 2007).

Segundo Maria Paula Meneses (2008, p. 5), com base nos escritos de Boaventura de Sousa Santos (1995, 1999, 2000, 2007, 2008, entre outros) que desde 1995 vem propondo uma discussão sobre a questão, "uma epistemologia do Sul assenta em três orientações: aprender que existe o Sul; aprender a ir para o Sul; aprender a partir do Sul e com o Sul". Para estes autores, a divisão radical a partir da hierarquização dos saberes atribuiu à ciência moderna o monopólio universal de dominância sobre o conhecimento, estabelecendo uma distinção entre o verdadeiro e o falso. Porém, a colonialidade do poder sobre o conhecimento vai além das contradições epistemológicas sobre o reconhecimento dos múltiplos saberes que permeiam as diferentes produções de sentido no campo científico. A relação colonial da circulação da produção científica é parte dos acordos de uma agenda global capitalista, no qual países hegemônicos reforçam sua centralidade a partir de práticas nas quais a natureza hierárquica das relações Norte Sul permanecem nas relações capitalistas e imperiais, como por exemplo o espaço destinado a publicação de produções do Sul Global nas revistas que foram paulatinamente reconhecidas como legitimadoras da qualidade científica, desde que reproduzissem modelos instaurados por escolas dos países centrais (Larivière et al., 2015); a falta de

\footnotetext{
2 Para o sociólogo da ciência, estas normas seriam pautadas em quatro princípios: 1) comunalismo (o conhecimento científico é um patrimônio comum da humanidade); 2) Universalismo (os trabalhos científicos devem seguir padrões universais de avaliação; 3 ) disinterestedness [isenção de interesses] (distanciamento da ciência para interesses pessoais); e 4) organized skepticism [ceticismo organizado] (o cientista deve ser privado de qualquer forma de preconceito e de conclusões precipitadas sobre seus trabalhos).
} 
espaço reservado aos sujeitos avaliadores de países periféricos e semiperiféricos, como comitês científicos nestas mesmas revistas (Dhanani \& Jones, 2017); a imposição sobre a reprodução de modelos metodológicos e as dependências infraestruturais de sistemas de mensuração e avaliação da ciência (Haustein, 2016). Estes são alguns dos exemplos da dominância do Norte sobre o Sul, através da colonização epistêmica naturalizada e desapercebida no qual as questões espacial e temporal são centrais a esta discussão. Ou melhor, a falta de espaço e temporalidades enredadas provocam a tangencialidade da ciência no Sul Global, como uma localidade expandida (Resende \& Thies, 2017) reconhecida e assumida como fundamental para entendermos que modelos específicos, estabelecidos e fixos atribuídos pela ordem política e econômica dominante se entrelaçam com os modelos pós-coloniais e desafiam a (des)ordem mundial (Levander \& Mignolo, 2011). Neste sentido, mais do que uma negação aos modelos dominantes, este olhar constitutivo sobre epistemologias do Sul convida a reformular os paradigmas de países coloniais a partir de perspectivas que exponham as disputas de poder e a naturalização ideológica da subalternidade, da exclusão e do estatuto periférico (Mata, 2014). As epistemologias do Sul, em suas perspectivas pós-coloniais, devem ser vistas como o encontro de diferentes concepções sobre o conhecimento e o poder (Santos, 2008).

Segundo Luciana Ballestrin (2013, p. 94), "a mudança na redefinição das esferas política e cultural na América Latina durante os anos recentes levou a vários intelectuais da região a revisar epistemologias previamente estabelecidas nas ciências sociais e humanidades", reconhecendo a necessidade do desenvolvimento de correntes epistemológicas oriundas de suas próprias dimensões locais, na busca por categorizações críticas para a região (Castro-Gómez \& Mendieta, 1998), visto que o continente latino-americano ocupa um espaço central para o exercício da colonialidade, pois foi a primeira periferia do sistema-mundo e também a primeira oportunidade de acumulação primitiva do capital (Castro-Gómez, 2005).

Para Cicilia Peruzzo (2016), a pesquisa participante, e em especial a pesquisa-ação, se insere no debate e nas propostas de descolonização da ciência, da emergência de uma epistemologia do Sul, por propor alternativas à produção de conhecimento a partir de modelos eurocêntricos, ao reconhecer a existência de múltiplos saberes e favorecer a formação de sujeitos críticos para fora das instituições universitárias (Maldonado-Torres, 2008). Assim, vemos emergir na América Latina a pesquisa-ação como uma das formas de conseguir compreender essa múltipla ecologia de saberes, ao trazer os sujeitos de investigação como agentes ativos e atuantes da produção de conhecimento, que não estão necessariamente inseridos no restrito espaço de produção de conhecimento científico. A pesquisa-ação reconhece os agentes da investigação como sujeitos (coletivos ou individuais), além "da potencialidade de construção de conhecimento científico na relação com os mesmos na condição de participantes ativos, como co-protagonistas - e não meros informantes/colaboradores - na elaboração de planos, interpretações e no empoderamento dos resultados" (Peruzzo, 2016, p. 6), possibilitando o reconhecimento de outros saberes na ecologia do conhecimento para além daquele impregnado pela racionalidade científica hegemônica. 
Desde os anos 2000, a pesquisa-ação vem crescendo no Brasil, conforme apontam Etienne Lima e Fábio Silva (2017). Partindo da compreensão de que a pesquisa-ação emerge neste cenário de uma epistemologia própria do Sul (Peruzzo, 2016), nos interessa investigar como este tipo de pesquisa vem sido configurado no Brasil, buscando responder se este tipo de investigação é uma das formas de produção do conhecimento próprias desse pensamento pós-abissal. Assim, nos interessa compreender como a pesquisa ação tem sido apresentada em produções científicas brasileiras? Qual é o perfil da pesquisa ação no Brasil? Essas são as questões que conduzem este trabalho. Nos interessa, portanto, investigar que tipos de práticas de pesquisa-ação estão sendo desenvolvidas no Sul Global, buscando tecer, a partir de métodos cartográficos, a consolidação de uma rede de investigação sobre o tema. Para tanto, como recorte inicial para esta pesquisa, teceremos um olhar sobre o Brasil, onde teve início deste tipo de pesquisa na América Latina, com as práticas investigativas no campo da educação em Paulo Freire na década de 1970 (Gajardo, 1985), cujo o crescimento sobre o interesse acadêmico brasileiro tem aumentado cada vez mais desde o século XXI (Lima \& Silva, 2017).

\section{EM BUSCA DE UMA CIÊNCIA INVISÍVEL E SUAS APROXIMAÇÕES COM UMA EPISTEMOLOGIA DO SUL}

Para a compreensão do ecossistema científico é necessário inicialmente reconhecer os múltiplos agentes que compõem as tramas relacionais da ciência. Dentre alguns atores que envolvem a circulação científica contemporânea estão as grandes editoras, responsáveis pela indexação das revistas científicas e por legitimar e validar a qualidade das publicações dos periódicos que constam em suas bases. Contudo, o mercado que se forma em torno dessas editoras tem-se tornado complexo, limitando a circulação científica apenas a um conjunto de empresas que dominam o cenário, formando um "oligopólio científico" (Larivière et al., 2015) a partir de um conjunto de seis grandes companhias: ACS, Reed-Elsevier, Springer, Wiley-Blackwell, Taylor \& Francis, e Sage. A consolidação desta indústria de publicação científica tem sido tema de muito debate dentro e fora da comunidade científica, especialmente em relação às altas margens de lucro das principais editoras, seus critérios pouco transparentes de avaliação de títulos e a publicação de produções de pesquisadores, em sua maioria, europeus e norte-americanos, silenciando e tornando invisível o conhecimento desenvolvido em outros países, sobretudo em áreas consideradas menos estratégicas para a agenda global (Wagner \& Wong, 2011).

O que observamos nesse cenário é uma organização pautada em uma geopolítica do conhecimento (Mignolo, 2008), na qual o capitalismo e a globalização ditam as posturas, posicionamentos e disputas de poder deste ecossistema científico global, onde as empresas editoriais dominam o mercado científico do conhecimento e ditam normas para a avaliação do impacto, da qualidade e da legitimação científica. Neste cenário regido pelo capitalismo, dois circuitos são estabelecidos de maneira em que se cria um abismo sobre o que é hegemônico e o que é periférico, ou seja, o que está do "outro lado da linha", invisibilizado nestes espaços "reconhecidos" pela ciência global através das 
disputas de poder. Ou seja, cria-se uma "ciência de qualidade" e uma ciência periférica, uma ciência que não é mensurável pelos modelos de avaliação científica, uma ciência praticamente "invisível". Resta-nos perguntar: invisível para quem?

Tal indagação vai ao encontro de Boaventura de Sousa Santos que defende que o pensamento moderno ocidental é abissal. Para o pesquisador (Santos, 2007, p. 71), existe um sistema de distinções pautado no regime de visibilidades e invisibilidades, cujas distinções "são estabelecidas por meio de linhas radicais que dividem a realidade social em dois universos distintos: o "deste lado da linha" e o "do outro lado da linha"". Para ele, a divisão se funda de tal maneira, que o que é considerado "do outro lado da linha" desaparece como realidade, tornando inexistente o que é produzido neste outro circuito. Esse abismo "consiste em conceder à ciência moderna o monopólio da distinção universal entre o verdadeiro e o falso em detrimento de (...) corpos de conhecimentos alternativos" (Santos, 2007, p. 47). Segundo o pensador português, é necessário democratizar e descolonizar o conhecimento, reconhecendo a importância de múltiplas epistemologias. Para tanto, é necessário admitir que o saber é uma ferramenta que deve ser servida para além dos espaços tradicionais de produção de conhecimento, a partir da noção de acesso aberto, partilha e compromisso público, elementos cruciais da ciência latino-americana (Vessuri, Guédon \& Cetto, 2014).

Ainda, o conhecimento pode ser representado através de múltiplas formas, “incluindo texto, imagem, números, história, música, drama, poesia, cerimônia e meditação" (Hall \& Tandon, 2017, p. 13). Portanto, torna-se importante apontar que a geopolítica do conhecimento, cuja visão colonialista permanece sendo reproduzida, precisa ser relativizada, levando em consideração os contextos culturais e as práticas de resistência e libertação através da própria investigação científica.

Mas, para isso, é necessário compreender a produção do conhecimento a partir de uma perspectiva descolonial, que "implica pensar a partir das línguas e das categorias de pensamento não incluídas nos fundamentos dos pensamentos ocidentais" (Mignolo, 2008, p. 305). Para Santiago Castro-Gómez (2005, p. 80), decolonizar a universidade latino-americana significa introduzir o pensamento pós-colonial através da incorporação da transdisciplinaridade e do pensamento complexo que permita um intercâmbio cognitivo entre a ciência ocidental e outras formas "pós-coloniais" de produção de conhecimento. Mais do que buscar uma superação das lógicas de colonialidade implicadas no prefixo "pós", a decolonização da universidade não se trata de uma "reversão do momento colonial pelo pós-colonial" (Colaço, 2012) e sim de um posicionamento de luta contínua de uma universidade mais aberta, plural e participante.

Portanto, não se trata apenas da negação sobre a investigação científica hegemônica ${ }^{3}$, mas a compreensão de que esses aportes não são o suficiente quando se entende a produção científica para além dos paradigmas e modelos de circulação científica tradicionais. Para compreender o que tem sido produzido em conhecimento é necessário, portanto, se reconhecer os espaços de produção de saberes em territorialidades que não

${ }^{3}$ Aqui compreendida como espaços de circulação científica tradicionais como portais de editoras de acesso fechado e bibliotecas indexadoras que corroboram para uma hegemonia do conhecimento sob princípios comerciais. 
fazem parte de um eixo hegemônico da ciência, desafio que esta pesquisa busca suplantar. Descolonizar a ciência significa ao mesmo tempo desvelar a lógica da colonialidade e da reprodução da matriz colonial do poder, como por exemplo, discutindo as questões de barreiras linguísticas, culturais e estruturais da própria cientometria ao passo em que se desconecta dos efeitos totalitários das subjetividades e categorias de pensamento ocidentais, buscando tecer métodos que deem conta da produção de saberes científicos em sua compreensão mais ampla. É neste sentido que Santiago Castro-Gómez (2007) propõe outros paradigmas baseados na transdisciplinaridade e pensamento complexo como modelos emergentes do diálogo transcultural de saberes entre a ciência ocidental e formas pós-ocidentais de produção de conhecimento.

Nesse sentido, surge a noção de um pensamento pós-abissal (Santos, 2007, p. 85) "como um aprender com o Sul usando uma epistemologia do Sul. Ele confronta a monocultura da ciência moderna com uma ecologia de saberes, na medida em que se funda no reconhecimento da pluralidade de conhecimentos heterogêneos". Este pensamento busca reconhecer a diversidade inesgotável de produções de conhecimento heterogêneas, para além daquela que é legitimada pelo racionalismo científico, propondo formas de construir uma epistemologia adequada que dê conta destes múltiplos saberes (sendo apenas um deles a ciência moderna, tal como a conhecemos). Ou seja, não se trata de uma negação da ciência moderna, mas do reconhecimento de que ela não é capaz de explicar a realidade e que pode reafirmar o abismo entre o que é legitimado por epistemologias próprias e validadas pelo racionalismo científico, numa distinção entre o que é "verdade científica" e o que é o popular. Nos deparamos com diferentes níveis de circuitos abissais no ecossistema científico: de um lado, uma separação pautada na geopolítica do conhecimento a partir de circuitos consolidados em torno de práticas capitalistas de um mercado editorial científico hegemônico, que distingue a circuitos da ciência hegemônica e da ciência periférica; e de outro, em subconjuntos locais, o fortalecimento da distinção entre o que é científico, e que se baseia em metodologias validadas pelos agentes hegemônicos da ciência, e o que está do "outro lado", o que é popular, o outro conjunto de saberes.

Diante dessa organização social da ciência, nos deparamos com a pesquisa-ação, que busca superar tais distinções, e construir uma epistemologia própria do Sul Global, propondo outra forma de se relacionar com o abismo entre o hegemônico e o periférico de ciência global, ao passo que reconhece a ecologia dos múltiplos saberes, unindo o conhecimento científico e o conhecimento popular, neste cenário de pensamento pós-abissal, respeitando as lógicas e as necessidades dos povos do continente latino-americano. Conforme aponta Cicilia Peruzzo (2016, pp. 6-7), "um novo modo de ver e de conceber a ciência, e de gerar conhecimento científico estão em construção na América Latina - e não só nela - desde pelo menos as últimas quatro décadas do século passado". Para a autora, a pesquisa-ação tem se aprimorado, buscando situar esse tipo de investigação no âmbito da epistemologia científica, desvencilhando-se de certos dogmas e tecendo métodos para qualificar a inserção do investigador para além da militância política. $A$ pesquisa-ação "dá credibilidade ao desenvolvimento de poderes de durações reflexivas, 
discussões, decisões e ações de pessoas comuns que participam de uma pesquisa coletiva sobre "problemas privados", que eles têm em comum (Adelman, 1993, p. 9).

Como sabemos, nenhuma ciência é neutra em seu caráter político, mas segue os interesses objetivos de classes sociais envoltas na formação, acumulação e disseminação por uma hegemonia do conhecimento (Fals Borda, 2012). A pesquisa-ação surge através de uma "busca de novas premissas na produção do conhecimento científico que relativiza o pressuposto de que o único conhecimento válido é o científico e que este só é possível ser obtido se for construído segundo os cânones do empirismo, da objetividade e da pretensa neutralidade, princípios estes construídos e reproduzidos a partir da cultura científica ocidental de cunho positivista" (Peruzzo, 2016, p. 5). A pesquisa-ação, portanto, diz respeito ao desenvolvimento de uma epistemologia na qual o pesquisador não apenas é um sujeito atuante na investigação, mas possui um equilíbrio de poderes entre os outros agentes envolvidos na experiência de pesquisa, uma natureza epistemológica do Sul Global.

\section{PRessupostos EPISTEMológicos dA PESQUisa-AÇÃo}

Diante deste cenário de disputas e oligopólios científicos, regidos pelo capitalismo e pela globalização (Mignolo, 2008, 2013), alternativas ao pensamento social latino-americano são concebidas em direção contrária à organização colonial do mundo. Uma colonialidade expressa pelo pensamento neoliberal que, segundo Lander (2005, p. 14), detém de uma força hegemônica que nutre uma noção de caráter objetivo e universal do conhecimento, a qual se articula "com as separações que estabelecem os conhecimentos sociais entre a sociedade moderna e o restante das culturas". Assim, um leque de alternativas aos saberes modernos se encadeia no contexto latino-americano em questionamento ao caráter colonial dos saberes sociais. O autor aponta que uma nova forma de se conceber o mundo em direção à abolição do regime de separação que marginaliza o continente. É uma compreensão de um paradigma que articula a ideia de comunidade, de libertação através da práxis, de redefinição do papel do pesquisador social, de caráter histórico, de pluralidade epistêmica, de resistência, e da revisão de métodos e transformações ocasionadas por ele (p. 15).

Neste sentido, diversas contribuições são identificadas com o propósito de compor o paradigma do pensamento social latino-americano no contexto da geopolítica do conhecimento. A pesquisa-ação se configura como uma dessas propostas por buscar uma convergência entre o pensamento popular e o conhecimento científico, por superar a distinção entre sujeito e objeto, uma característica do positivismo, e por se inspirar num conceito democrático pluralista (Fals Borda, 2012). Assim, aplicada em vários campos do conhecimento e com finalidades distintas, a pesquisa-ação, que se posiciona no contexto científico como uma proposta metodológica de reinvenção das metodologias tradicionais, nos apresenta a ação e a conduta do pesquisador dentro do processo investigativo como elementos fundamentais na elaboração de uma pesquisa. Desta forma, há uma íntima relação entre os sujeitos considerados e a ação proposta, acompanhada de 
uma transformação social que se revela como característica central desta metodologia (Thiollent, 2009).

A pesquisa-ação surge no período pós segunda guerra mundial, se popularizando na América Latina em meados da década de 1960. Sua fundamentação teórica e epistemológica tem raiz na Alemanha, a partir do psicólogo Kurt Lewin, que acreditava ser a pesquisa-ação uma importante estratégia de intervenção psicológica. Judeu e indignado com a opressão nazista, Kurt se posicionou como defensor da mudança social, propondo uma metodologia em seus estudos acadêmicos que fosse útil para a sociedade, com justiça social e investigação rigorosa: a pesquisa-ação (Melo et al., 2016). Contudo, apesar da atribuição do termo dada por Lewin, existem divergências sobre o criador do processo (Tripp, 2005). Por vezes, na literatura científica, a pesquisa-ação é tida como qualquer tipo de reflexão sobre a ação, desconsiderando o caráter da pesquisa-ação como uma forma de investigação-ação que requer ação tanto na área prática como na pesquisa.

Para Barbier (1985), a pesquisa-ação se revela no contexto pós-guerra para dar conta de questões relevantes para a conjuntura social da época, assim como os Estados Unidos fez após a primeira guerra mundial, investigando problemas sociais em zonas urbanas. É nesta concepção que a pesquisa-ação reflete sobre o lugar do homem na sociedade e propõe uma transformação dos objetos em sujeitos sociais, tornando a produção do saber coletiva e identificando uma gênese social que precede a gênese teórica. A finalidade é servir de instrumento de mudança social (Barbier, 2007), sem desagregar a produção do conhecimento da prática desempenhada para se chegar à mudança.

Assim, a metodologia da pesquisa-ação se apresenta diante de uma lacuna entre a teoria e a prática. Apesar do termo pesquisa-ação ser amplamente utilizado, Peruzzo explica que por vezes outras denominações são empregadas como "pesquisa-ação participativa, ou simplesmente de pesquisa participante, pesquisa ativa, estudo- pesquisa, investigação-ação ou pesquisa militante, segundo a visão de cada autor e das tradições teóricas que as fundamentam" (2016, p. 2). Sob uma ótica participante, Peruzzo discorre sobre essas discrepâncias conceituais e o uso de todos estes termos. A autora parte da pesquisa participante para compreender as especificidades da pesquisa-ação, que se enquadra como uma modalidade de pesquisa participante (assim como a observação participante), a qual tem como pressuposto básico a inserção do pesquisador no ambiente do fenômeno e/ou grupo estudado, e a sua interação com ele. Porém, no caso específico da pesquisa-ação, Peruzzo acrescenta que "o pesquisador, não só compartiIha do ambiente investigado, mas possibilita que o investigado participe do processo de realização da pesquisa e que os resultados se revertam em benefício do próprio grupo pesquisado" (2003, p. 3). Em contrapartida, apesar dos rumos atuais da pesquisa participante, que ainda é de constante busca pela legitimidade científica, precisamos considerar a complexidade deste campo metodológico, que parte de muitos debates sobre a inserção do pesquisador no ambiente investigado e essa forma de se conceber e fazer pesquisa em Ciências Humanas, mesmo a pesquisa participante sendo aplicada em várias áreas do conhecimento, como na educação, sociologia, comunicação, na antropologia, administração, engenharia, entre outras. 
Não se trata de um abandono de um modelo de dominação científica na forma de atuação na pesquisa, mas de uma transformação, ou ainda transfiguração, dos modelos hegemônicos na reconstrução de planos científicos. Fals Borda enaltece qual deve ser o papel verdadeiro do cientista ativo de hoje que coloca em cheque questões relevantes anteriores ao resultado da pesquisa como: "qual é o tipo de conhecimento que queremos e precisamos?"; "A que se destina o conhecimento científico e quem dele se beneficiará?" (1981, p. 47). Contudo, o mesmo autor acrescenta que a intenção não é formar um novo paradigma científico por meio da pesquisa participante, substituindo um já existente, mas sim questionar a necessidade de uma centralidade no processo de produção do conhecimento científico, muito mais do que no produto final.

No entanto, podemos nos aproximar de um tipo de brecha metodológica se os pesquisadores engajados seguirem os efeitos dinâmicos do rompimento da díade sujeito-objeto que esta metodologia exige como uma de suas características básicas. São muito evidentes as potencialidades de se obter um novo conhecimento sólido a partir do estabelecimento, na pesquisa, de uma relação mais proveitosa sujeito-objeto, isto é, uma completa integração e participação dos que sofrem a experiência da pesquisa. (Fals Borda, 1981, p. 59)

Portanto, propomos uma discussão epistemológica e metodológica inovadora de valorização do fazer científico, apresentando a pesquisa-ação como uma proposta que dialoga com a inovação e a empiria. A pesquisa-ação é uma proposta libertadora e emancipatória no sentido de libertar quanto "à imposição dos hábitos, dos costumes e da sistematização burocrática" (Barbier, 2007, p. 59). Queremos nos distanciar de um discurso de universalidade da ciência e de neutralidade da produção científica. "A ciência é histórica, se move, avança e se transforma em conformidade com o próprio processo histórico das civilizações. Portanto, se a ciência não é unívoca, também não o é a epistemologia da ciência", o que implica a pesquisa participante baseada em um afastamento do positivismo e aproximação de uma visão dionisíaca (Peruzzo, 2016, p. 4). Essa noção de epistemologia, segundo Peruzzo, ajuda na compreensão das controvérsias que acompanham o conhecimento científico e a sua validação, corroborando para uma noção com uma dimensão ainda maior, a de uma epistemologia do Sul, que tem na pesquisa participante "portas de entrada para a construção de conhecimentos", diante do contexto e das lógicas científicas latino-americanas.

Portanto, este parece ser um momento pertinente para darmos mais ênfase em uma breve apresentação dos pressupostos gerais da pesquisa-ação, em virtude da sua clara proposta de ruptura com os cânones do empirismo e modelos construídos e sustentados pela cultura científica ocidental a partir de um modelo de espirais de reflexão e ação. Para essa breve discussão, tomamos como base características gerais da pesquisa-ação apontadas por Peruzzo (2016, p. 9), que destaca a "participação/inserção do pesquisador, o tipo de ação, a participação do investigado e o retorno dos resultados". 


\section{PARTICIPAÇÃo/INSERÇÃo do PESQUisador}

Fazer pesquisa-ação requer uma participação contínua e efetiva do pesquisador dentro do cenário e da realidade do fenômeno e/ou grupo estudado. Barbier (1985) posiciona a pesquisa-ação como uma corrente que não apenas se afasta do positivismo, mas que propõe uma sociologia do acontecimento ou da cotidianidade. Assim, a participação do pesquisador tem como foco acompanhar a dinâmica do cotidiano, de modo que ele também tenha autonomia para agir. Para que essa interação ocorra é preciso uma autorização prévia do grupo ou da comunidade.

A inserção é uma fase de aproximação com o grupo e ocorre quando o pesquisador assume a função de coordenador da pesquisa. Função esta que deve se distanciar da relação "opressor e oprimido" ou "educandos e educados", qual é levantada por Paulo Freire (2005). Aplicar a pesquisa-ação é se afastar do sistema da "educação bancária", onde educar se torna $o$ ato de depositar o saber, que desconsidera a consciência e o processo dialético, mas sim aproximar-se de uma pesquisa na perspectiva libertadora. $O$ pesquisador não é um "capacitador" do grupo estudado, mas um "mediador", apesar de autônomo e autor da sua prática e do seu discurso, que está presente com a finalidade de desenvolver um papel ativo na resolução dos problemas encontrados, no acompanhamento e na avaliação.

\section{TIPO DE AÇÃo}

A ação a que se refere a pesquisa-ação é dupla: ação do pesquisador e ação do grupo estudado. Peruzzo (2016), explica que essa ação se distingue daquela convencional na concepção da pesquisa etnográfica, observação participante e correntes antropológicas e psicológicas tradicionais. Na pesquisa-ação, o pesquisador não apenas observa, mas também tem livre atuação, centrada na cooperação e coletividade com os sujeitos do grupo pesquisado. Na definição de Thiollent (2009, p. 16), a pesquisa-ação é concebida e realizada com "estreita associação com uma ação ou com a resolução de um problema coletivo e no qual os pesquisadores e os participantes representativos da situação ou do problema estão envolvidos de modo cooperativo ou participativo".

\section{PARTICIPAÇÃo do INVESTIGAdor}

O pesquisador tem um papel ativo dentro da pesquisa-ação, que tem como pressuposto não separar o pesquisador do pensamento e da ação, dos fatos e valores. O envolvimento entre o pesquisador e os sujeitos integrantes da pesquisa resulta em vários níveis de envolvimento. Assim, a participação dos investigados não é tida como mera ação colaborativa, mas em ações que partem desde a elaboração estratégica de um plano de ações, à realização efetiva da pesquisa e debate sobre os dados obtidos com os resultados. É uma participação calcada não apenas nos interesses do pesquisador, mas em uma contribuição efetiva e contínua para os sujeitos investigados, a partir de uma construção de conhecimento coletivo e, assim, propondo uma descolonização do conhecimento. 
A pesquisa-ação tem a intenção de superar as lógicas do conhecimento científico tradicional ao incorporar uma função político-social, o que vai de encontro com a participação do investigador na efetivação da pesquisa-ação. Thiollent (2009) associa essa função política a uma ação ou resolução de um problema que deve ter como princípio básico a coletividade e cooperatividade, onde os sujeitos investigados têm algo a dizer ou fazer. A investigação e a condução do investigador e investigados está diretamente ligada à uma proposta de política de transformação. Contudo, é preciso também considerar as limitações existentes neste processo e reconhecer os aspectos estruturais da realidade social investigada. As ações só podem estar estruturadas e serem transformadoras se os sujeitos envolvidos estiverem conscientes de todas essas questões. Além disso, essas transformações são necessariamente limitadas, tendo em vista que o sistema social não é alterado definitivamente e as transformações aqui evocadas pela pesquisa-ação ocorrem diretamente na consciência das pessoas.

A justa apreciação do alcance das transformações associadas à pesquisa-ação não passa por critérios únicos. Cada situação é diferente das outras. Quando as ações adquirem uma dimensão objetiva de fácil identificação (por exemplo: produção, manifestação coletiva etc.), os resultados podem ser avaliados em termos tangíveis: quantidade produzida, número de pessoas mobilizadas etc. A ação é acoplada à esfera dos fatores subjetivos e, portanto, faz-se mister distinguir vários graus na tomada de consciência.

(Thiollent, 2009, p. 47)

\section{RETORNO DOS RESULTADOS}

O retorno do conhecimento é um dos grandes diferenciais da pesquisa-ação, afastando-a da proposta normativa de conceber a ciência tradicionalmente e da concepção de "laboratório", rompendo com todos esses padrões científicos. O retorno do resultado da pesquisa é muitas vezes esperado pelos grupos estudados, mas raramente devolvido. Na pesquisa-ação, esse retorno ocorre em todo o processo investigativo e em uma última etapa com uma linguagem clara e acessível para a compreensão de todos. Peruzzo (2016, p. 13) explica que a pesquisa-ação pressupõe uma democratização desses resultados ao longo da pesquisa porque "os próprios passos delineados vão possibilitando a participação na discussão de "achados" pois se realizam fóruns e seminários para apresentação e discussão de resultados parciais e organização interna da pesquisa".

Sobre a democratização desse conhecimento e o retorno dos resultados da pesquisa, Fals Borda (1981) acrescenta que deve ser sistematizado, organizado e sem arrogância intelectual, propondo algumas regras de "restituição sistemática". A primeira regra trata de uma comunicação diferencial, que deve ser adaptada de acordo com o nível de desenvolvimento político e educacional do grupo estudado. A segunda determina uma simplicidade da comunicação, priorizando uma linguagem acessível a todos. Em seguida, o autor sugere uma auto investigação e controle, ou seja, um controle do processo 
investigativo pelo grupo investigado. Esta regra chama a atenção para a autonomia controlada do pesquisador, que não pode decidir sozinho o que deve ser investigado, mas sim tomar esta decisão juntamente com os sujeitos do grupo pesquisado, partindo de relações dialogais e rompendo o esquema objeto e sujeito da pesquisa. Por fim, a última regra pressupõe uma popularização técnica científica, reconhecendo as técnicas de pesquisa e apresentando-as de forma acessíveis aos grupos.

\section{Cartografias da pesquisa-aÇÃo no Sul Global}

Novos modos de se ver e conceber o conhecimento científico estão em constante construção na América Latina, isto é, modos alternativos ao pensamento eurocêntrico-colonial. O continente passa por uma mudança de perspectiva ao se colocar "no lugar de Nós" (Lander, 2005). Uma epistemologia do Sul tem sido formada, ficando evidente a urgência de uma reflexão epistemológica. Para Santos (2007, p. 20), nunca esteve tão claro "que a compreensão do mundo é muito mais ampla que a compreensão ocidental do mundo", o que explica o contexto de globalização e de debilidade das teorias sociais. O grande problema para quem vive no Sul é que as teorias ocidentais não se ajustam às realidades dos países que não fazem parte do eixo hegemônico.

Uma discrepância entre teoria e prática social revelam a emergência de uma epistemologia do Sul - a descolonização da ciência - e trazem à tona a necessidade de um novo modo de produção de conhecimento (Santos, 2007). Neste contexto, propostas metodológicas participativas ganham força como uma alternativa às novas formas de conceber o pensamento, sendo a pesquisa-ação um desses caminhos possíveis, por ultrapassar os limites da ação e fortalecer a tomada de consciência por meio do empoderamento participativo e reflexivo. Além de gerar respostas concretas a problemáticas do grupo investigativo, a pesquisa-ação permite a expansão de processos de construção do conhecimento, se estabelecendo com uma "nova visão da sociedade, do conhecimento e da ciência" (Colmenares, 2012).

Partindo deste cenário, visando entender esse processo de construção de conhecimento a partir de metodologias participativas no Sul Global, realizámos uma coleta de publicações científicas na América Latina sobre pesquisa-ação divulgadas nos últimos 17 anos (2000-2017), visto que estudos apontam para um crescimento sobre o tema desde os anos 2000 (Lima \& Silva, 2017). O intuito é investigarmos que tipos de práticas de pesquisa-ação estão sendo desenvolvidas no Sul, buscando tecer, a partir de métodos cartográficos, a consolidação de uma rede de investigação sobre o tema.

Por entender o pouco espaço de publicação de artigos brasileiros e latino-americanos em periódicos do oligopólio científico, nossa coleta buscou utilizar outras maneiras de se mensurar a circulação da produção científica sobre o tema, visto que as buscas tradicionais bibliométricas utilizando a Web of Science ou Science Direct da Scopus não permitem acolher o panorama científico em regiões periféricas (Wagner \& Wong, 2012). Assim, esta pesquisa buscou utilizar outras fontes, como o Google Acadêmico, que permite uma mensuração mais ampla das pesquisas brasileiras (Mugnaini \& Strehl, 2008), 
ainda que o rigor científico para a indexação não seja muito relevante. Para tanto, utilizamos o software Publish or Perish para a extração dos dados, realizando uma busca pelos títulos “investigación acción" (951) e "pesquisa-ação" (856), totalizando 1.807 títulos categorizados. Por meio do software, de cada publicação, obtivemos o número de citações, autor, título, ano, fonte, editor, URL do artigo, URL da citação, dentre outros dados. Para a realização de uma investigação mais aprofundada, iremos nos debruçar sobre os dados referentes à pesquisa-ação, que compreende a realidade científica brasileira.

De todo o conjunto de entradas identificadas $(n=856)$ foram localizados apenas dois títulos indexados pelas grandes editoras comerciais que fazem parte do oligopólio científico, representando $0,35 \%$ do total de títulos encontrados nessa amostra, reforçando a ideia da existência de uma ciência invisibilizada no mercado científico. Os dois títulos da amostra presentes no circuito do oligopólio científico estão indexados na Elsevier. As bases de indexação que aparecem com maior ênfase nos demais títulos analisados são Redalyc, SciELO Brasil e Bireme, que são bases relevantes no contexto da América Latina (Babini, 2011). O Action Research Journal4, por exemplo, é um periódico que pertence a uma dessas grandes editoras que comandam esse oligopólio científico, a Sage, e há somente duas publicações de autores latino-americanos nos últimos três anos nas edições publicadas. No comitê editorial há um único membro da América Latina, do México, apesar de ter vários membros do Sul Global. Apesar do interesse no tema, e de uma tradição do uso de pesquisa-ação em alguns campos do conhecimento como a educação, por exemplo, que vem tido destaque desde os trabalhos de Paulo Freire Fals Borda na década de 1970, pesquisadores latino-americanos possuem pouco espaço nas revistas de grandes editoras comerciais como a Sage, seja na publicação ou no espaço de avaliação e legitimação da qualidade do material a ser publicado. Esta breve análise sobre os últimos três anos de publicação da Action Research Journal nos mostra o quanto a ciência latino-americana costuma ser invisibilizada e tangenciada nos espaços de grande circulação científica, e portanto, necessário desenvolver outras metodologias para mensuração da ciência para além das plataformas amplamente utilizadas como Web of Science e Scopus.

A coleta se baseou em duas buscas a partir de palavras-chave: Pesquisa-ação, para coleta de publicações de pesquisadores brasileiros e Investigación-Acción, para pesquisadores latino-americanos, excluindo publicações de pesquisadores oriundos da Espanha e de outros países de língua castelhana. Tal procedimento teve como intuito entender quantitativamente como tem evoluído a discussão sobre pesquisa-ação em países da América Latina, incluindo o Brasil, buscando, posteriormente, aprofundar sobre os perfis de publicação apenas nas produções brasileiras.

Quanto às suas características, o primeiro gráfico (Gráfico 1) nos apresenta um panorama da pesquisa-ação (Brasil) e da investigación acción (países latino-americanos) no período de 2000 a 2017 , sendo possível observarmos uma estabilidade de publicações de pesquisa-ação no Brasil nos últimos cinco anos e um declínio na investigación acción no restante da América Latina no mesmo período. Apesar de a pesquisa estar

4 Disponível em http://journals.sagepub.com/home/arja 
centrada nestes dois termos, do ponto de vista conceitual, as nomenclaturas variam de acordo com as tradições teóricas. Peruzzo (2016) nos explica que a pesquisa-ação (ou Investigação-ação) é uma expressão com origem anglo-saxônica (action-research) e francesa (recherche-action), particularmente a partir das investigações de Kurt Lewin, sendo a América Latina bastante influenciada pelo termo Pesquisa Participante. No contexto brasileiro, são destacados Paulo Freire, Carlos Rodrigues Brandão e João Bosco Pinto, com a expressão pesquisa participante num primeiro momento. Em um segundo momento, predomina a denominação pesquisa-ação com Michel Thiollent e o próprio Fals Borda, entre outros.

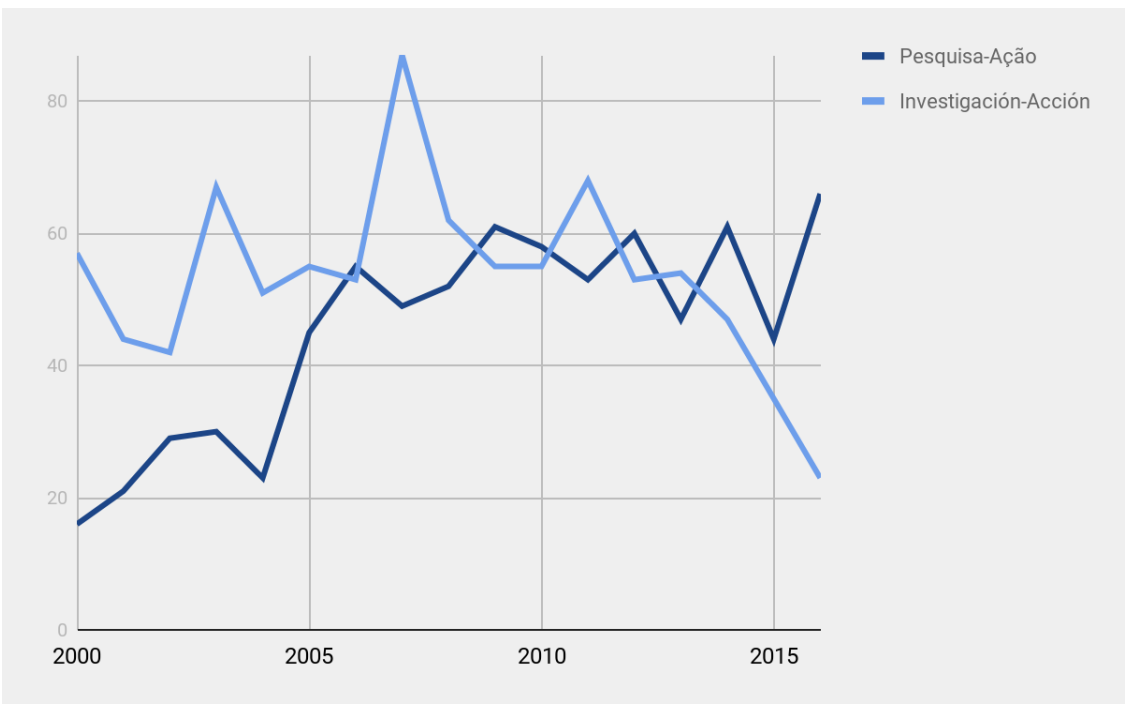

Gráfico 1: Evolução da pesquisa-ação e da investigación acción

A partir desta análise, podemos perceber o crescimento do interesse sobre a pesquisa-ação no Brasil, justificando nosso recorte sobre a investigação a partir do que tem sido publicado sobre o assunto no país. Não queremos dizer com isso que este é um tipo de investigação típica do Brasil, pois a produção científica dos países são diversas e respondem à agendas locais em cada campo do conhecimento. Assim como também não é possível afirmar que a pesquisa-ação é um fenômeno exclusivo do Brasil, pois como apontado anteriormente, muitas pesquisas com recurso a este método têm surgido a partir de pesquisadores de diferentes nacionalidades, como na revista Action Research, por exemplo. Contudo, o crescimento deste tipo de pesquisas nos mostra um interesse recorrente no país, em diferentes áreas do conhecimento.

Apesar das diferentes expressões para denominar a pesquisa-ação nos mais distintos contextos, não há um valor único e específico para defini-la. A multidisciplinaridade e as mais variadas apropriações da prática de pesquisa são características que definem a essencialidade da pesquisa-ação, que pode vir a servir para distintos interesses a depender da sua finalidade e corrente epistemológica. Como resultado deste caráter interdisciplinar, podemos visualizar na prática, na realidade científica brasileira, as apropriações das práticas do processo de investigação propostas pela pesquisa-ação em diferentes 
áreas do conhecimento (Gráfico 2). Para esta categorização, tomamos como base a divisão de áreas do conhecimento definida pelo Conselho Nacional de Desenvolvimento Científico e Tecnológico ( $\mathrm{CNPq}$ ), assim, dividindo os títulos em oito grandes áreas: Agrárias, Letras Linguística e Artes (LLA), Saúde, Biológicas, Sociais Aplicadas, Exatas e da Terra, Humanas e Engenharias.

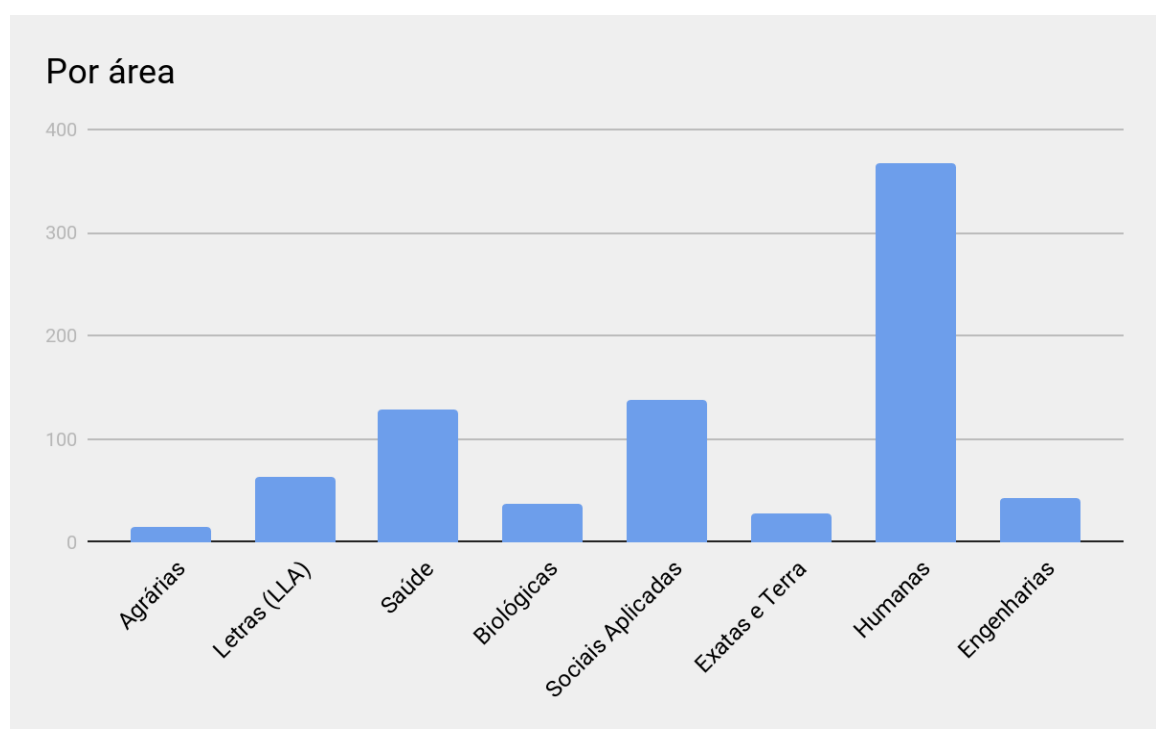

Gráfico 2: Pesquisa-ação por área do conhecimento

As categorias de áreas do conhecimento foram levantadas para dividirem didaticamente o material extraído, mas é importante ressaltarmos que por vezes elas se interligam, o que ocorre devido a existência de títulos com caráter multidisciplinar 5 . Assim, observamos que algumas produções poderiam ser classificadas em mais de uma categoria e, dessa forma, levamos em consideração expressões e palavras-chaves contidas nos títulos das publicações para a realização de uma categorização individualizada em todos os arquivos listados.

Como podemos observar no gráfico acima, as produções sobre pesquisa-ação na área de Humanas se destacam diante das demais áreas, contabilizando 368 títulos. A grande maioria das produções nesta categoria enquadram-se na temática Educação, refletindo uma tendência dos primórdios dos estudos da pesquisa-ação no Brasil, proposto sobretudo por Paulo Freire, da sua utilização frequente para aplicação e compreensão de práticas pedagógicas educativas, apesar de atualmente assumir um caráter multidisciplinar. Segundo Barbier (2007, p. 19), que é um importante estudiosa da pesquisa-ação e a sua aproximação com as instituições educativas, essa relação é um reflexo de características pedagógicas e políticas da pesquisa-ação, servindo como base para a educação do homem cidadão preocupado com a organização coletiva da cidade. Assim, por excelência, ela faz parte da categoria da formação.

\footnotetext{
5 Reconhecemos, portanto, a limitação deste estudo na categorização proposta, que buscou levar em consideração às particularidades e multidisciplinariedade comum na pesquisa-ação.
} 
Seguindo o processo de categorização por área do conhecimento, temos a categoria Sociais Aplicadas (137 títulos) e, posteriormente, a Saúde (129 títulos), com poucos títulos distanciando uma da outra. A aproximação é uma resposta de tentativas de consolidação da pesquisa-ação em diferentes áreas de aplicação, resultando em uma performance multidisciplinar com distintas vertentes teórico-metodológicas. Por exemplo, Tripp (2005) é um grande defensor da utilização da pesquisa-ação por pesquisadores das Ciências Humanas e Sociais. Já na área da saúde, Sommer (1999) e Williamson e Prosser (2002) destacam o uso desse aporte metodológico para mudanças práticas e geração de novos conhecimentos a partir do empoderamento dos seus participantes no área da saúde, apesar de levantarem algumas ressalvas como aspectos éticos (Melo et al., 2016). Thiollent (2009) aponta algumas das áreas de aplicação da pesquisa-ação como, por exemplo: educação, comunicação, serviço social, desenvolvimento rural, práticas políticas, além de chamar atenção para a aplicação em áreas mais técnicas como engenharia de produção, agronomia, arquitetura, dentre outras.

Somente as áreas de Saúde, Humanas e Sociais Aplicadas têm publicações em todos os anos analisados. No que diz respeito às temáticas desses títulos, existe um predomínio de discussões teórico-metodológicas em quase todas as áreas do conhecimento, sendo este também os títulos com o maior número de citações, que correspondem a livros e capítulos, não contabilizados pelas grandes empresas que dominam o "oligopólio científico" (Larivière et al., 2015), desfavorecendo a própria mensuração do impacto científico das produções em pesquisa-ação, invisibilizando a produção de conhecimento a partir de uma epistemologia que une conhecimento científico e conhecimento popular. Esse panorama científico representa também um papel que vem sendo desempenhado pelo Sul na construção do conhecimento científico com fortes influências das lógicas científicas do Ocidente, tornando-se necessário uma reinvenção da emancipação social a partir do Sul por meio de uma organização fora dos centros hegemônicos (Santos, 2007).

A relação Universidade-Sociedade é um outro traço observado no perfil da pesquisa-ação na realidade brasileira. O termo universidade surge na Idade Média para denominar qualquer corporação que agregasse um conjunto de sujeitos com um mesmo propósito, sem necessariamente possuir o caráter institucional das universidades modernas. Para Leonor Paini, bastava que os alunos estivessem vinculados a um mestre e seguissem seus ensinamentos para que essa agregação fosse chamada de schola ou "família". As "universidades", em seu sentido amplo na época, poderiam acontecer em qualquer lugar, e “o saber era considerado um 'Dom' divino e, como tal, caberia a qualquer cristão que fosse agraciado por Deus e tivesse assim o Dom do conhecimento do latim" (Paini \& Costa, 2016, p. 60). Apesar disso, conforme aponta Leonor Paini, já havia uma monetização do conhecimento, visto que os universitários pagavam as aulas ministradas pelos mestres.

De acordo com Chauí (2003), a universidade moderna se consolida após a revolução francesa e no século XIX seu caráter de ensino e pesquisa é constituído. No Brasil, as primeiras escolas especializadas foram criadas junto com a transferência da sede monárquica portuguesa para o país, sem, contudo, se configurar como universidade. 
Até a Proclamação da República, o modelo de ensino superior fora pautado em formação de profissionais liberais e "o objetivo era o de garantir um diploma profissional com vistas a garantir certo prestígio social e a ocupação de postos privilegiados em um restrito mercado de trabalho" (Paini \& Costa, 2016), que foi reforçado com o projeto de modernização do país nas décadas de 1920/1930. Nesta época, como em modelos de extensão de outros países que surgem de crises políticas e econômicas, a universidade passou a englobar uma terceira função, para além das já consolidadas de ensino e pesquisa: a extensão, que na década de 1980 foi compreendida no Brasil como um processo educativo, cultural e científico que articula o Ensino e a Pesquisa de forma indissociável e viabiliza a relação transformadora entre Universidade e Sociedade (Forproex, 2002). Através da extensão, a universidade "tem papel de transferência de conhecimento e mobilização comunitária, de modo que o conhecimento teórico adquirido na universidade, somado à possibilidade da vivência prática, seria capaz de gerar transformações, em resposta a lacunas de mercado" (Bachmann \& Parisotto, 2016, p. 2). Contudo, é justamente neste período de redemocratização do país que esta terceira missão da universidade por sua extensão começa a adquirir novas configurações, sobretudo em função de um estreitamento de parcerias entre a universidade pública e as empresas privadas, visando financiamento de pesquisas que atendam aos seus interesses mútuos. Neste sentido, o mercado vem surgindo com um importante ator na consolidação do ethos universitário, sobretudo em função de mudanças nas políticas públicas que deram abertura ao incentivo à inovação no país. Tais disputas sobre os domínios desta terceira função da universidade vão ao encontro do que Boaventura de Sousa Santos aponta como conhecimento-emancipação e conhecimento-regulação. Para ele,

um conhecimento compreensivo e íntimo que não nos separe e antes nos una pessoalmente ao que estudamos. Não se trata do espanto medieval perante uma realidade hostil possuída do sopro da divindade, mas antes da prudência perante um mundo que, apesar de domesticado, nos mostra cada dia a precariedade do sentido da nossa vida, por mais segura que esta esteja quanto à sobrevivência, sendo que para a esmagadora maioria da população mundial não o está. (Santos, 2000, p. 84)

Para o autor, o projeto da modernidade se baseia em duas formas de conhecimento: emancipação e regulação. O pilar do conhecimento-regulação é composto pelo Estado, pelo mercado e pela comunidade/sociedade, enquanto que na emancipação é possível identificar três formas de racionalidade: a estético-expressiva, a cognitivo-instrumental e por último a racionalidade prático-moral do direito. Na contemporaneidade, vemos o conhecimento emancipação ser absorvido pela regulação, a partir da convergência entre modernidade e capitalismo e sua racionalização baseada na ciência moderna. Para Boaventura de Sousa Santos, esta sobreposição do conhecimento-regulação sobre o conhecimento-emancipação ocorreu através da imposição da racionalidade científica e da regulação de mercado sobre o Estado e à comunidade, tornando, assim, a racionalidade científica hegemônica e o mercado o único princípio regulador moderno que atravessa 
todas as esferas da sociedade. Indo a este encontro, Moisés Martins (2015, p. 407) aponta que o contexto da mercantilização e datificação também têm afetado o pensamento na universidade: "elas [as universidades] estão sujeitas à mesma cinética do mundo, a da mobilização tecnológica para o mercado, o que quer dizer, a da resposta às exigências de uma civilização dos números". Para o autor, este movimento de transformação do conhecimento em mercadoria potencial para atender às demandas do mercado, tem fragilizado a própria pesquisa, que em nome da 'accountability', vem sido medida por seu "valor económico", mais ainda do que seu "valor científico" tradicionalmente mensurável através de citações.

Para romper com essa imposição da regulação e emancipar o conhecimento são necessários novos modelos paradigmáticos nos quais seja possível transformar o conhecimento científico (totalizante e antidemocrático) em um novo senso comum, definido por Boaventura, como "conhecimento prudente para uma vida decente". Este entendimento vai ao encontro do que Jésus Martin-Barbero denuncia sobre a existência de brechas cognitivas que desvelam a cumplicidade mantida desde há mais de dois séculos entre o monoteísmo racionalista do cientificismo e o mercantilismo que a rentabiliza. Para o autor, a convergência começou a desgastar o poder sobre o conhecimento, estabelecido pelo racionalismo cientificista, no qual os pesquisadores se mantêm "entrincheirados no seu didatismo autoritário" (2014, p. 5) com pouco diálogo com a sociedade. Ainda que Barbero entenda a convergência a partir de uma concepção tecnológica, a diluição das fronteiras dos "tradicionalmente modernos" circuitos do conhecimento, ultrapassam a tecnicidade e convergem para outros sentidos: na transdisciplinaridade, na multiplicidade de atores sociais e no reconhecimento da existência de diversos saberes, ao descolocar a hierarquização do conhecimento cientificista.

É neste sentido que a pesquisa-ação aparece como um modelo possível de emancipação do conhecimento, ao integrar a comunidade e a ciência, o mercado e o Estado, como vemos no gráfico abaixo.

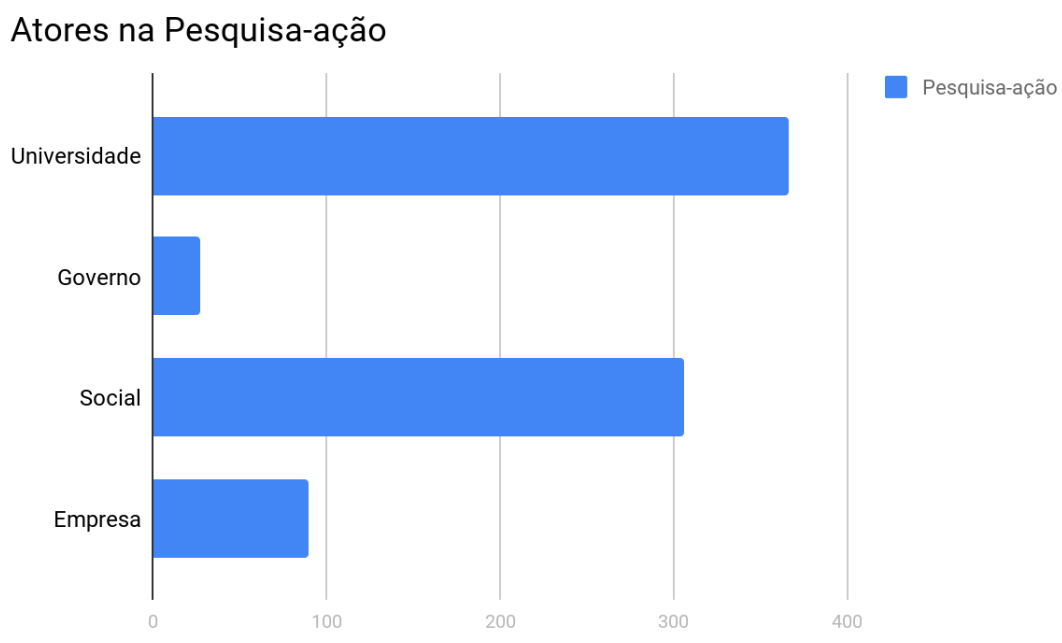

Gráfico 3: Participação dos quatro atores na pesquisa-ação 
Nesta junção de diferentes atores possíveis de serem contemplados pela pesquisa-ação, vemos emergir um tipo de pensamento pós-abissal, um tipo de conhecimento emancipatório, que busca integrar a multiplicidade da ecologia de saberes científicos e populares. Tal relação descrita (Gráfico 3) é baseada no modelo organizacional da Hélice Tríplice criado em 1990 por Henry Etzkowitz e Leot Leydesdorff, qual é referência nas discussões sobre processos de inovação, cujo objetivo é descrever a inovação na relação entre as instituições universidade-empresa-governo (Etzkowitz, 2003), considerando múltiplos processos na construção e disseminação do conhecimento onde "cada Hélice é uma esfera institucional independente, mas trabalha em cooperação e interdependência com as demais esferas, através de fluxos de conhecimento" (Gomes \& Pereira, 2015, p. 138).

Nesta proposta, consideramos para a categorização da amostra desta pesquisa a universidade com o papel de fornecer neste sistema não apenas sujeitos habilitados e resultados de pesquisas, mas, anterior a isso, um capital intelectual que the fornece um status diferenciado em uma sociedade baseada no conhecimento (Etzkowitz, 2003). Assim, toda produção com mais ênfase teórica e reflexiva foi enquadrada nessa categoria. Já o Governo tem a função de investir em políticas públicas para o fortalecimento das relações no modelo da Hélice Tríplice (Souza da Silva, Rocha \& Silva, 2013), sendo identificado na análise nos títulos que se direcionam a proposições que investem em políticas públicas. "As Empresas devem priorizar a responsabilidade social e o empreendedorismo através da gestão da inovação em serviços, produtos, técnicas etc" (Souza da Silva et al., 2013, p. 11). Desta forma, notamos a categoria empresa diante de produções com caráter comercial, mas que tratam de ações que promovam a responsabilidade social e o empreendedorismo.

Apesar de centrar-se numa ação que indica três elementos fundamentais para o desenvolvimento da sociedade, a categoria Social não é contemplada pelo modelo tradicional da Hélice Tríplice criado por Etzkowitz e Leydesdorff. Para Lindberg, Danilda e Torstensson (2012) uma quarta hélice pode ser identificada: a sociedade ou o setor público, incluindo mídia, indústria criativa, cultura, valores, estilo de vida e arte, que, segundo eles, também influenciam no sistema de inovação e não são contemplados no modelo tradicional. Desta forma, consideramos nesta análise a quarta hélice, a Sociedade, identificando os títulos onde os valores e as demandas sociais eram priorizados.

\section{CONSIDERAÇÕES FINAIS}

A pesquisa-ação no Brasil possui outras características para além das bases dos pilares científicos estabelecidos pelas regras da ciência dominante. Observamos que há uma predominância de uma relação universidade-sociedade, refletido por uma maior participação na área de Humanas nos títulos sobre pesquisa-ação publicados no período estudado. O sujeito está na centralidade do estado da arte da pesquisa-ação como uma de suas características básicas, distanciando-se da dicotomia sujeito-objeto amplamente difundida pela ciência hegemônica e tradicional. Assim, o caráter social das publicações expressa uma tentativa do Sul de rompimento de barreiras sustentadas pela 
ciência Ocidental, inserindo a pesquisa-ação como uma proposta de decolonização da ciência e de uma epistemologia do Sul (Santos, 2007).

Contudo, apesar do caráter social aparecer com forte incidência nos títulos coletados nesta revisão sistemática, há também uma quantidade elevada de trabalhos com direções teórico-metodológicas da pesquisa-ação, sendo estes os mais citados, o que é um problema substanciado pela epistemologia do Sul, onde "para uma teoria cega, a prática social é invisível; para uma prática cega, a teoria social é irrelevante" (Santos, 2007, p. 20). Portanto, há uma tendência de apagamento da prática social em relação à teoria por influência das lógicas científicas ocidentais consolidadas como uma epistemologia do Sul. Como resultado, notamos pesquisas com pouca aplicabilidade da pesquisa-ação na esfera social prática, deixando de cumprir com o papel elementar da pesquisa-ação que é o da transformação da realidade investigada e dos sujeitos pesquisados. Contudo, isto não significa negar a consolidação de um percurso da pesquisa-ação nos últimos anos no Brasil, tendo em vista um notório crescimento da proposta metodológica que fica evidente no material de análise desta pesquisa. Acredita-se que a racionalidade técnica das lógicas acadêmicas tem grande contribuição nesse processo. No contexto da descolonização da ciência, precisamos de um modo novo de se produzir conhecimento (Santos, 2007) e a pesquisa-ação se insere nesse debate como uma forma alternativa de se conceber o conhecimento, porém, não fica imune às lógicas acadêmicas de produção e circulação científica. As exigências científicas se multiplicam quando nos referimos à pesquisa-ação, isto porque existe uma dificuldade em conciliar os prazos científicos com os prazos de uma pesquisa-ação. O tempo do homem da ação não é o mesmo do homem dos estudos, se revelando em normas científicas que condizem com as perspectivas de uma "qualidade" acadêmica, que segue uma lógica de "ideologia comercial" onde "as universidades são empresas; a educação são serviços; o ensino e a investigação são oportunidades de negócios; os professores são profissionais de serviços ou consultores; os alunos são clientes" (Martins, 2015, p. 409).

É a partir de uma realidade com dinâmica social que a pesquisa-ação pode ser realizada, propondo uma radicalização epistemológica e diferenciando-se de outras pesquisas tradicionais. Deste modo, ela desempenha um papel de ordem prática que implica a resolução de uma série de fatores, evidenciando seu caráter multidisciplinar (Barbier, 1985). Neste contexto, conseguimos categorizar os títulos em oito áreas do conhecimento definidas pelo CNPq, predominando a área de Humanas e Sociais Aplicadas, seguida da Saúde. Os principais temas abordados pela saúde no que se refere à pesquisa-ação são Enfermagem, Saúde da Família e Educação Física. Os resultados obtidos com a categorização por área revelam a metamorfose da pesquisa-ação que percorre não apenas em diferentes campos de aplicação do conhecimento, mas também o "campo da epistemologia da ciência que transita entre práticas inovadoras de pesquisa empírica, porém distantes do empirismo, e os questionamentos epistemológicos do próprio fazer científico" (Peruzzo, 2016, p. 3).

Buscando tecer uma cartografia da pesquisa-ação no Brasil, observamos ainda que os estudos sobre tal temática têm se estabilizado nos últimos cinco anos, tendendo 
para um possível crescimento progressivo. Muito se tem debatido sobre as estratégias de inserção do pesquisador no ambiente pesquisado, mas pouco se tem apresentado e aprofundado em discussões teórico-metodológicas no contexto brasileiro. Acreditamos ser essa uma necessidade urgente, visando uma circulação mais rápida e efetiva do conhecimento da pesquisa-ação para a formação de uma rede metodológica científica mais forte e descolonizada das práticas científicas tradicionais.

Buscamos nesta pesquisa discutir sobre a pesquisa-ação como uma das possibilidades de desenvolvimento de uma epistemologia do Sul, na qual possa se atrelar o conhecimento científico e outras ecologias de saberes. Ainda que os pressupostos da pesquisa-ação nos permitam refletir sobre a emergência de epistemologias do Sul e sua relação com o reconhecimento de múltiplos saberes para além do conhecimento acadêmico imposto pela racionalidade científica, o que pudemos observar é que este tipo de pesquisa ainda carece de mais espaço para discussão, não apenas nos circuitos já consolidados e dominados pelos países hegemônicos, como a revista Action Research, publicada pela Sage, mas também de outros espaços científicos voltados para o assunto a partir de produções e perspectivas emergentes dos países periféricos.

A discussão sobre a pesquisa-ação está diretamente implicada em pressupostos científicos, colonialismo do saber e a ideia de uma ciência invisível, ou melhor, numa ciência invisibilizada a partir de pressupostos metodológicos da racionalidade científica e de uma geopolítica do conhecimento que invisibiliza outras formas de produção dos múltiplos saberes. No Sul Global, há uma necessidade de rever a forma de se avaliar a ciência, não apenas pelo valor do impacto científico e de inovação, mas também para a inclusão de uma concepção que leve em consideração o impacto social da ciência.

\section{REFERÊNCIAS BIBLIOGRÁFICAS}

Adelman, C. (1993). Kurt Lewin and the origins of action research. Educational Action Research, 1, 7-24. doi: $10.1080 / 0965079930010102$

Babini, D. (2011). Acceso abierto a la producción científica de América Latina y el Caribe: identification of main institutions for regional integration strategies. Revista Iberoamericana de Ciencia Tecnología y Sociedad, 6(17), 31-56. Retirado de http://biblioteca.clacso.edu.ar/gsdl/collect/clacso/index/assoc/ D4662.dir/babini_EDITADO_FINAL.pdf

Bachmann, A. \& Parisotto, I. (2016). Extensão universitária e inovação social: estudo em uma universidade pública municipal. In Anais do Engema - Encontro Internacional sobre gestão empresarial e meio ambiente (pp. 1-15). São Paulo: Universidade de São Paulo.

Ballestrin, L. (2013). Decolonial turn and Latin America. Revista Brasileira de Ciência Política, 11, 89-117. doi: $10.1590 /$ So103-33522013000200004

Barbier, R. (1985). A pesquisa-ação na instituição educativa. Rio de Janeiro: Jorge Zahar.

Barbier, R. (2007). A pesquisa-ação. Brasília: Liber Livro Editora.

Castro-Gómez, S. \& Mendieta, E. (1998). Teorías sin disciplina: latinoamericanismo, poscolonialidad y globalización en debate. México: Miguel Ángel Porrúa. 
Castro-Gómez, S. (2005). Ciências sociais, violência epistêmica e o problema da "invenção do outro". In E. Lander (Ed.), A colonialidade do saber: eurocentrismo e Ciências Sociais. Perspectivas latino-americanas (pp. 80-87). Buenos Aires: Colección Sur Sur.

Castro-Gómez, S. (2007). Decolonizar la universidad. La hybris del punto cero y el diálogo de saberes". In S. Castro-Gómez \& R. Grosfoguel (Eds.), El giro decolonial. Reflexiones para una diversidad epistémica más allá del capitalismo global (pp. 79-91). Bogotá: lesco-Pensar-Siglo del Hombre Editores.

Chauí, M. (2003). A universidade pública sob nova perspectiva. Revista brasileira de educação, 24, 5-15. Retirado de http://www.scielo.br/pdf/rbedu/n24/n24a02.pdf

Colaço, T. (2012). Novas perspectivas para a antropologia jurídica na América Latina: o direito e o pensamento decolonial. Florianópolis: Fundação Boiteux.

Colmenares, A. (2012). Investigación-acción participativa: una metodología integradora del conocimiento y la acción. Voces y Silencios, 3, 102-115. Retirado de https://revistas.uniandes.edu.co/doi/pdf/10.18175/ vys3.1.2012.07

Dhanani, A. \& Jones, M. (2017). Editorial boards of accounting journals: gender diversity and internationalisation. Accounting, Auditing Q Accountability Journal, 30(5), 1008-1040. doi: 10.1108/ AAAJ-08-2014-1785

Etzkowitz, H. (2003). Innovation in innovation: the triple helix of university-industry government relations. Social Science Information, 42 (3), 293-337. doi: 10.1177/05390184030423002

Fals Borda, O. (1981). Aspectos teóricos da pesquisa participante: considerações sobre o significado e o papel da ciência na participação popular. In C. R. Brandão (Ed.), Pesquisa participante (pp. 42-62). São Paulo: Brasiliense.

Fals Borda, O. (2012). La praxis: ciencia y compromiso. In H. Armando. \& L. López. (Eds.), Ciencia, compromiso y cambio social. Textos de Orlando Fals Borda (pp. 147-205). Buenos Aires: El Colectivo.

Freire, P. (2005). Pedagogia do oprimido. Rio de Janeiro: Paz e Terra.

Forproex. (2012). Política Nacional de Extensão Universitária, do Fórum de Pró-Reitores de Extensão das Instituições Públicas de Educação Superior Brasileira (FORPROEX). Retirado de http://proex.ufsc.br/ files/2016/04/Pol\%C3\%ADtica-Nacional-de-Extens\%C3\%A3o-Universit\%C3\%A1ria-e-book.pdf

Gajardo, M. (1985). Teoría y práctica de la educación popular. México: Organización de Estados Americanos.

Gomes, M. \& Pereira, F. E. (2015). Hélice tríplice: um ensaio teórico sobre a relação Universidade-EmpresaGoverno em busca da Inovação. International Journal of Knowledge Engineering and Management, 4(8), 136-155. Retirado de http://incubadora.periodicos.ufsc.br/index.php/IJKEM/article/view/3309

Hall, B. \& Tandon, R. (2017). Decolonization of knowledge, epistemicide, participatory research and higher education. Research for All, 1, 6-19. doi: 10.18546/RFA.01.1.02

Lander, E. (2005). Ciências sociais: saberes coloniais eurocêntricos. In E. Lander (Ed.), A colonialidade do saber: eurocentrismo e Ciências Sociais. Perspectivas latino-americanas (pp. 8-23). Buenos Aires: Colección Sur.

Larivière, V., Haustein, S. \& Mongeon, P. (2015). The oligopoly of academic publishers in the digital era. PloS one, 10(6). doi: e0127502

Levander, C. \& Mignolo, W. (2011). Introduction: the global south and world dis/order. The Global South, 5 , 1-11. doi: 10.3998/jar.0521004.0067.202 
Lindberg, M., Danilda, I. \& Torstensson, B.-M. (2012). Women resource centres: a creative knowledge environment of quadruple helix. Journal of the Knowledge Economy, 3(1), 36-52. doi: 10.1007/ s13132-011-0053-8

Lima, E. \& Silva, F. (2017). Pesquisa-ação na formação inicial de professores de matemática. Revista Saberes Docentes, 2, 1-22. Retirado de http://www.revista.ajes.edu.br/index.php/RSD/article/view/212

Maldonado-Torres, N. (2008). A topologia do ser e a geopolítica do conhecimento. Modernidade, império e colonialidade. Revista Crítica de Ciências Sociais, 80, 71-114. Retirado de https://journals.openedition.org/ $\operatorname{rccs} / 695$

Martín-Barbero, J. (2014). "Tudo o que sabemos, sabemo-lo entre todos" "Aquela segunda oportunidade sobre a terra" - Algumas palavras para não faltar completamente. Revista Lusófona de Estudos Culturais, 2(1), 4-6. Retirado de http://www.rlec.pt/index.php/rlec/article/view/51/44

Martins, M. (2015). A liberdade académica e os seus inimigos. Comunicação e Sociedade, 27, 405, 420. doi: $10.17231 /$ comsoc.27(2015).2109

Mata, I. (2014). Estudos pós-coloniais. Desconstruindo genealogias eurocêntricas. Civitas - Revista de Ciências Sociais, 14, 27-42. doi: 10.15448/1984-7289.2014.1.16185

Melo, A., Maia Filho, O. \& Chaves, H. (2016). Lewin e a pesquisa-ação: gênese, aplicação e finalidade. Factal, 28, 153-159. doi: 10.1590/1984-0292/1162

Meneses, M. P. (2008). Epistemologias do Sul. Revista Crítica de Ciências Sociais, 80, 5-10. Retirado de http:// journals.openedition.org/rccs/689

Merton, R. (1968). The Matthew effect in science. Science, 159(3810), 56-63. doi: 10.1126/science.159.3810.56

Merton, R. (1972). The sociology of science: theoretical and empirical investigations. Chicago: University of Chigaco Press.

Mignolo, W. (2008). Desobediência epistêmica: a opção descolonial e o significado de identidade em política. Cadernos de Letras da UFF - Dossiê: Literatura, língua e identidade, 34, 287-324. Retirado de http://www.uff.br/cadernosdeletrasuff/34/traducao.pdf

Mignolo, W. (2013). Geopolítica de la sensibilidad y del conocimiento. Sobre (de) colonialidad, pensamiento fronterizo y desobediencia epistémica. Revista de Filosofía, 74(2). Acedido em http://eipcp.net/ transversal/o112/mignolo/es

Mugnaini, R. \& Strehl, L. (2008). Recuperação e impacto da produção científica na era Google: uma análise comparativa entre o Google Acadêmico e a Web of Science. Encontros Bibli: Revista Eletrônica de Biblioteconomia e Ciência da Informação (Vol. Especial), 92-105. doi: $10.5007 / 1518-2924.2008 \mathrm{v} 13$ nesprpg2

Paini, L. \& Costa, L. (2016). A função social da universidade na contemporaneidade: algumas considerações. Eventos Pedagógicos, 7, 59-72. Retirado de http://sinop.unemat.br/projetos/revista/index.php/eventos/ article/viewFile/2077/1701

Peruzzo, C. (2003). Da observação participante à pesquisa-ação em Comunicação: pressupostos epistemológicos e metodológicos. In Anais do XXVI Congresso Brasileiro de Ciências da Comunicação (pp. 1-23). Belo Horizonte: Intercom - Sociedade Brasileira de Estudos Interdisciplinares da Comunicação.

Peruzzo, C. (2016). Epistemologia e método da pesquisa-ação. Uma aproximação aos movimentos sociais e à comunicação. In Anais XXV Encontro Anual da Compós (pp. 1-22). Goiânia: Compós - Associação Nacional dos Programas de Pós-Graduação em Comunicação. 
Resende, F. \& Thies, S. (2017). Temporalidades enredadas no Sul Global. Revista Contracampo, 36 (3), 1-19. doi: 10.22409/contracampo.v36i3.1095

Santos, B. D. S. (1995). Toward a new common sense: law, science and politics in paradigmatic transition. Nova lorque e Londres: Routledge.

Santos, B. D. S. (1999). Um discurso sobre as ciências. Porto: Afrontamento.

Santos, B. D. S. (2000). A crítica da razão indolente. São Paulo: Cortez.

Santos, B. D. S. (2007). Para além do pensamento abissal: das linhas globais a uma ecologia de saberes. Novos Estudos-CEBRAP, 79, 71-94. doi: 10.1590/S0101-33002007000300004

Santos, B. D. S. (2008). Renovar a teoria crítica e reinventar a emancipação social. São Paulo: Boitempo.

Sommer, R. (1999). Action research: from mental hospital reform in Saskatchewan to community building in California. Canadian Psychology/Psychologie Canadienne, 40(1), 47-55. doi: 10.1037/hoog2490

Souza da Silva, H., Rocha, E. \& Silva, W. (2003). Inovar para desenvolver: relação entre os atores universidade, empresa e governo. Examãpaku, 6(2), 1-14. doi: 10.18227/1983-9065ex.v6i2.2022

Thiollent, M. (2009). Metodologia da pesquisa-ação. São Paulo: Cortez.

Tripp, D. (2005). Pesquisa-ação: uma introdução metodológica. Educação e Pesquisa, 31(3), 443-466. Retirado de http://www.scielo.br/pdf/ep/v3ın3/aogv3ın3.pdf

Vessuri, H., Guédon, J. \& Cetto, A. M. (2014). Excellence or quality? Impact of the current competition regime on science and scientific publishing in Latin America and its implications for development. Current Sociology, 62(5), 647-665. doi: 10.1177/0011392113512839

Wagner, C. \& Wong, S. (2011). Unseen science: representation of BRICs in global science. In 2011 Atlanta Conf on Science and Innovation Policy, Atlanta, September 15-17, 2011.

Williamson, G. \& Prosser, S. (2002). Action research: politics, ethics and participation. Journal of Advanced Nursing, 40 (5), 587-593. doi: 10.1046/j.1365-2648.2002.02416.x

\section{NOTA BIOGRÁFICA}

Lumárya Souza de Sousa - Mestranda do Programa de Pós-graduação em Comunicação da Universidade Federal Fluminense. Membro do Laboratório de Experiências de Engajamento e Transformações da Audiência (Leeta). Editora assistente da Revista Contracampo. Tem como temática da dissertação em andamento a democratização do conhecimento a partir do projeto de pesquisa aplicada Favelação, desenvolvido no Morro do Estado, em Niterói-RJ, Brasil. Tem trabalhado em iniciativas de democratização do conhecimento como o Dose de Ciência comemorado no Dia D da ciência, Pint of Science, entre outros.

E-mail: lumaryas@gmail.com

Morada: Rua Aurelino Leal, 105, Ap 904 - Centro - Niterói/RJ - Brasil. Cep: 24020-110. 
Thaiane Oliveira - Professora do Programa de Pós-graduação em Comunicação da Universidade Federal Fluminense. Coordenadora do Laboratório de Investigação em Ciência, Inovação, Tecnologia e Educação (Cite-Lab), que abriga o Laboratório de Experiências de Engajamento e Transformações da Audiência (Leeta) e o Núcleo de Estudos Estratégicos de Circulação e Políticas Científicas (Nepc).

E-mail: thaianeoliveira@id.uff.br

Morada: Rua Cacilda Ouro, 783 - Itaipu - Niterói/RJ - Brasil. Cep: 24342-220.

* Submetido: 30.11 .2017

* Aceite: 15.03 .2018 